laws, to administer them faithfully and conscientiously, and ever to lend a. willing ear to every suggestion of possible injustice and probable reform. It rests with our profession now to blot out this abuse from our statute books, and to make our laws, in this respect, equal in justice and policy, as we believe they are in most respects superior, to those of the other civilized nations of the earth.

Troy, N. Y., Norember, 1865.

B.

\title{
PATENT AND LATENT AMBIGUITIES IN WRITTEN INSTRUMENTS.
}

AN ambiguity is a doubtfulness or uncertainty of signification from a word's being susceptible of different meanings. In law the term has received a more extensive signification, and relates to circumstances extrinsic and beyond the definition of a word.

Although there is some confusion among the authorities, there is nevertheless a broad and plain distinction between patent and latent ambiguities in written instruments.

By the term patent ambiguity, in its broadest sense, may be understood an ambiguity appearing on the face of the instrument. Its frequent use in this way, in connection with the general proposition that a patent ambiguity admits of no explanation by matters extrinsic, has occasioned no inconsiderable degree of confusion, and led Mr. Justice STORY to think there must be an intermediate class of ambiguities, comprising those instances where the words are equivocal and yet admit of precise and definite application, by resorting to the circumstances under which the instrument was made. As an example, he puts the case of a written contract, assigning the party's interest in the freight of a ship; saying parol evidence would be admissible of the circumstances attending the transaction, to ascertain whether the word "freight" referred to the goods on board the ship or to an interest in the earnings of the ship. This, however, falls exactly within the general definition of a patent ambiguity. The terms used are în themselves of doubtful meaning, and consequently admit of more than one interpretation according to the subject matter in contemplation of the parties. The ambiguity is not latent 
in any proper sense, It arises from the known infirmity of language, it is inherent in the instrument, appearing on its face, and evincing a difficulty at the very moment of its perusal. And yet it admits of explanation. The courts of law admit evidence of particular usages and customs, in aid of the interpretation of written instruments, whenever from the nature of the case a knowledge of such usage and customs is necessary to a right understanding of the instrument. Parol evidence may also be given to apply the written instrument to the subject-matter, when used by particular persons and applied to particular subjects. It is perfectly right and, consistent with fair dealing to give effect to language used in a contract as it is understood by those who make use of it.

Our object, howrever, is to point out the distinction between patent and latent ambiguities. In order more clearly to mark that difference, it will be necessary to note that there are.two kinds of patent ambiguities, and a correct knowledge of these is essential in order to aroid their confusion with latent ambiguities; which latter are of a perfectly distinct kind. Some patent ambiguities allow a resort to extrinsic evidence, and others do not, and this latter class only seem appropriately to belong to the ambiguitas patens of which Lord Bacon writes. An ambiguity is patent in this sense, when the mere perusal of the instrument shows plainly that something more must be added before the reader can determine which of several things is meant by it; and then the rule is inflexible that no evidence to supply the deficiency can be admitted. The admission of such evidence in many cases would be, as Lord Bacon said, "to make that pass without deed, which the law appointeth shall not pass but by deed." In other words, it would be departing from the great leading principle which prevails on this subject, and allowing oral evidence to come in and ascertain that which the writing has left to the widest latitude of conjecture. The Master of the Rolls, in the case of Colpoys v. Colpoys, Jacob 451, has directly pointed out the fallacy of saying, that a patent ambiguity is one which admits of no explanation by extrinsic evidence. "When the person or thing is designated," he said, "on the face of the instrument, by terms imperfect and equivocal, admitting either of no meaning at all by themselves, or of a variety of different meanings referring tacitly or expressly for the ascertainment and completion of the meaning to extrinsic circumstances, it has never been considered an objection to the reception of the evi 
dence of those circumstances that the ambiguity was patentmanifest on the face of the instrument."

When a legacy is given to a man by his surname, and the Christian name is not mentioned, is not that a patent ambiguity? Yet it is decided that evidence is admissible. So where a gift is of the testator's stock, that is ambiguous. It has different meanings when used by a farmer and a merchant.

The definition of a patent ambiguity in $2 d$ vol. Stark's Ev. falls short of supplying a practical test, by which to determine, a priori, whether a given instance of ambiguity apparent on the face of the mriting is explainable or not by extrinsic evidence. It will not do to say, therefore, that a patent ambiguity (meaning thereby merely an ambiguity appearing on the face of the instrument) cannot be explained by evidence aliunde. Though such remarks are frequent in the books.

A patent ambiguity in a written instrument, which requires that something be added in order to make it intelligible, cannot be explained by evidence extrinsic, and renders the instrument void.

But where an expression is used capable of being satisfied in more ways than one, there is an ambiguity on the face of the instrument, and extrinsic evidence is admissible; "for the law is not so unreasonable as to deny to the reader of an instrument the same light which the writer enjoyed."

It may happen, and frequently does, that the very evidence introduced to elucidate an explainable patent ambiguity, shall result in bringing to light a latent ambiguity, not before known to exist.

A latent ambiguity would seem at first view to be easily understood, and yet a difficulty may arise with respect to that also from the loose manner in which the term has sometimes been used. Perhaps the clearest definition of this species of ambiguity is the one given by Mr. Sugden. "Ambiguitas latens," he says, " is that which seems certain and without ambiguity, for anything on the face of the instrument, but there is some collateral matter out of the instrument that breeds the ambiguity." And as it is raised by extrinsic evidence, it may be fairly dissolved by the same means. It is in the nature of a latent ambiguity never to appear on the face of the writing, but to lie hidden in the person or thing, or subject whereof the writing speaks. The location of lands where the boundaries are distinctly pointed out in the deed, has been called explaining a latent ambiguity (6 Mass. Rep. 441); 